\title{
E-learning Readiness Analysis (ERA): an e-health case study of e-learning readiness
}

\section{Jeanne Schreurs*}

Faculteit Toegepaste Economische Wetenschappen

Hasselt University, Diepenbeek Campus

Agoralaan gebouw D, B3590 Diepenbeek, Belgium

E-mail: Jeanne.Schreurs@ uhasselt.be

*Corresponding author

\section{Ulf-Daniel Ehlers}

Information Systems for Production and Operations Management

University of Duisburg-Essen, Essen Campus

Universitaetsstrasse 245141 Essen, Germany

E-mail: ulf.ehlers@web.de

\section{George Sammour}

Transportation Research Institute (Instituut voor Mobiliteit - IMOB)

Hasselt University, Diepenbeek Campus

High-Tech Park (Wetenschapspark) 5

Bus 6 BE-3590 Diepenbeek, Belgium

E-mail: George.sammour@uhasselt.be

\begin{abstract}
Electronic learning (e-learning) is seen as a good solution for organisations that deal with fast-changing knowledge and for reducing the cost of training. E-learning is a good opportunity for companies but it needs to be well prepared because it often takes high investment costs. That is why it is important for a company to know if it is e-ready. E-readiness is already well covered in the literature and several models are suggested. We used these models to develop an e-learning readiness measurement instrument and questionnaire. We used our instrument to check whether the Flemish hospitals were e-ready for e-learning.
\end{abstract}

Keywords: electronic learning; e-learning; semantic; electronic health; e-health; e-learning readiness analysis; ERA; electronic readiness; e-readiness.

Reference to this paper should be made as follows: Schreurs, J., Ehlers, U-D. and Sammour, G. (2008) 'E-learning Readiness Analysis (ERA): an e-health case study of e-learning readiness', Int. J. Knowledge and Learning, Vol. 4, No. 5, pp.496-508.

Biographical notes: Jeanne Schreurs is a Professor at the Faculteit Toegepaste Economische Wetenschappen, Universiteit Hasselt, Campus Diepenbeek, Belgium. 
Ulf-Daniel Ehlers is an Adjunct Associate Professor at the Graduate School for Management and Technology, the University College of the University of Maryland (USA) and the Vice President of the European Foundation for Quality in E-Learning.

George Sammour is a $\mathrm{PhD}$ student of Business Informatics at the Transportation Research Institute of Hasselt University, Belgium.

\section{Introduction}

The promises of e-learning for organisations are manyfold. Too often, they fail to take effect. The reason is not the sufficient readiness to take up e-learning in organisations and absorb the innovation effects that come along with it, but in their rush to implement e-learning, many organisations are making unfortunate mistakes. In this paper, we suggest e-learning readiness as a key factor influencing the uptake of e-learning in organisations. We present the E-learning Readiness Analysis (ERA) tool and discuss the results of its application to a case study in the healthcare sector.

In the globalised world of the $21 \mathrm{st}$ century, organisations are confronted with challenging economic competition. Employees need to be equipped with new competences to adapt to constantly changing work and life conditions in knowledge-based economies and societies. Organisations are aware of the value of knowledge and learning for their continual development and the acquisition of a competitive advantage, which relates to innovation and fulfilment. The healthcare sector is a fast-changing environment and it is clear that its performance depends on the ability of the staff to rapidly update their competences in order to adapt to a constantly changing environment (Psycharis, 2005; Bernhardt et al., 2003). Looking at e-learning in today's organisations, it can be defined as the delivery of instructional content or learning experiences enabled by electronic technology and it is one of the major innovations that diffuses corporate settings. E-learning requires that the learners use the internet, collaborate with peers and interact with the trainer for support. Experienced e-learners can even use technology to monitor their training and ultimately become responsible managers of their own personal and career development. The number of e-learning initiatives in corporate training scenarios is steadily increasing. The reasons are related to the cost of training and reports show that e-learning contributed to travel costs savings and downtime for workplaces. Advantages such as asynchronous training, training at an individual pace, just-in-time training and cost-effectiveness lure organisations to e-learning (Powell, 2000). The opportunity to learn via technology presents an exciting prospect to train even learners with little previous access to computer-based training. E-learning is a good opportunity for organisations that deal with fast-changing knowledge, but companies needs to be well prepared because it often takes high investment costs. 


\section{Introducing e-learning readiness}

Organisations have to be ready to adopt e-learning and benefit from its advantages. Such e-readiness can be defined as 'how ready the organisation is on several aspects to implement e-learning'. E-learning readiness should be determined before organisations introduce e-learning. Readiness includes learners' ability to adapt to technological challenges, collaborative training and synchronous as well as asynchronous self-paced training. It also depends on their motivation and discipline to learn in a self-driven mode and respond to online instructions. E-readiness makes up the e-maturity of the organisation, which also is represented in the readiness of learners. It includes the availability of infrastructure, clear training objectives, trainer support and guidance and knowledgeable leadership. Therefore, readiness from the learner, trainer and the organisation is required to successfully engage e-learning (Bowles, 2004).

\subsection{Strategy to improve learners' online experience}

In the study of Ipsos MORI (2006), the key components of e-learning readiness have been identified: social context, content delivery, technology access, learning style, collaboration capacity, organisational learning environment and personal motivation. Over two-thirds of the employees would like to see their organisation make more use of e-learning. Three in four feel that e-assisted training could be useful to them as trainers or to the other trainers in their organisation. The employers who are more sceptical say that they are limited by resources; half feel that they do not have the budget, while three in five believe that the employees will just not be interested. The key reason why some employers are sceptical about the potential of e-learning is that of technical resources. One of the main barriers to effective e-learning is the lack of accessible computers at the workplace. To improve learners' online experience, strategies need to be found that address the five areas of difficulty encountered by people which diminish the quality of their experience and may make people less inclined to e-learning (Ipsos MORI, 2006). The five areas of difficulty are:

1 the technical means

2 autonomy in web use

3 e-skills

4 the level of social support

5 variation in motivation.

Some cross-cutting components influence how people perceive barriers to e-learning and, therefore, how ready they feel they are to participate in it. The influencing components are the organisational culture, self-belief, computer competence and computer training.

\subsection{E-readiness assessment}

The literature on the organisational readiness for e-learning provides managers with questions, guidelines, strategies, models and instruments for assessing the readiness of their companies. E-readiness can be assessed by evaluating an individual's technical 
experience with and competency in interacting with computers. This competency should be supported by the individual's capability to direct his or her own training through the appropriate knowledge, skills, attitudes and habits. Aydin and Tasci (2005) suggested a questioning tool with seven categories:

1 human resources

2 learning management system

3 learners

4 content

5 IT

6 finance

7 vendor.

\subsection{Models to measure e-learning readiness}

The questions that arise here are: How to find a comprehensive concept to measure the e-readiness of organisations? Which criteria can be included? If we examine the models that can be found in the literature closely, we see certain common parameters that always come back. Also, Psycharis suggested three large categories (Psycharis, 2005): resources, education and environment. Each category contains certain criteria. In the resources category, the technological readiness, economic readiness and human resources readiness are investigated. Education means the readiness of content and the educational readiness. Environment includes entrepreneurial readiness, leadership readiness and the readiness of culture.

- $\quad$ resources - First of all, we want to investigate the technological readiness of the available technological systems that are provided and the way they are used. Economic readiness examines the willingness of the organisation to invest in e-learning. Implementing e-learning brings along large costs and the organisation needs to be prepared to make the necessary investments in the infrastructure, but also foresee a degree of administration support. Human readiness refers to the knowledge and skills of the employees being the e-learners. An important question is if the staff has the necessary basic skills and if they feel at ease with the used technology and the necessary investments in infrastructure, but also foresee a degree of administration support.

- education - Whether or not an organisation is ready from an educational point of view will be determined by the measurement of the readiness of the content. Is the educational content easily available, is it well structured and is it reusable? Educational readiness is also important. It is about the learning styles and educational needs of the employees.

- environment - The criteria of this category are the entrepreneurial readiness and the readiness of the culture. The Flemish hospitals in our case study all have their own authority on decision making on how they train their staff. 


\subsection{Characteristics of good e-learning delivery in the social care sector}

A research study conducted by the Social Care Institute for Excellence (SCIE) ${ }^{1}$ concluded that some of the components required of an organisation to deliver an advanced e-learning system for its staff have been established. The result suggests that without these components being put in place by organisations, barriers will form and inhibit the e-learning experience.

The influencing factors of how e-learning is facilitated within organisations are:

- $\quad$ how training is valued in practice

- the time allocated for training

- how the staff is supported.

Suitable content delivery requires:

- the skill level of instructors

- the availability and accessibility of specialised e-learning materials

- an assessment of learner competencies

- the development of an effective learner management system.

The required technological elements are:

- the hardware available to staff

- internet connectivity

- $\quad$ how flexible the system is to engage with all the web-based material.

A good match between the type of training and the learners' characteristics is based on:

- $\quad$ an effective assessment of the preferred learning styles

- $\quad$ an open attitude on the part of the trainer towards different combinations of e-learning and other techniques.

The required elements for a collaborative e-learning approach:

- the technical systems required to connect learners together

- the way online communities are established and maintained

- the processes and procedures to share knowledge and experiences and the way all of these work together so that all learners can access them.

The general training characteristics of the organisation:

- learning culture

- evaluation of impact of learning

- the ability to influence staff motivation. 


\subsection{Building the ERA instrument}

Studying the already existing theory and using our insights on e-learning and the quality aspects of e-learning, we developed an e-learning readiness measurement instrument. A self-assessment questionnaire has to be built on it. This questionnaire can slightly be changed and adopted according to the sector in which it is used, if necessary.

We developed a questionnaire and used it to measure the e-learning readiness in hospitals. We developed a set of questions based on our self-assessment quality questionnaire (Schreurs et al., 2008).

Our instrument consists of enabling or delivery criteria and results criteria. The enabling criteria are about the creation of the environment in which e-learning can be implemented. It is about the preparation of the learners and about the management of learning in the organisation.

The results criteria are about the level of preparedness to implement e-learning in the organisation. It is about the learners' characteristics, the availability of technological facilities, the investments done by management and the quality of the e-learning solutions and processes themselves.

\subsubsection{The enabling criteria}

Figure 1 The enabling criteria of the e-learning readiness measurement model

1. Enabling the employees/learners to participate in an e-learning course

- Assessment of learners competence

- Assessment of preferred learning style

- Motivating employees

- Organise and manage procedures and processes to share knowledge and experience in learning

- $\quad$ Optimise the learning process and the role of e-learning in it.

\section{Training activity in the organisation is a management issue}

- How training is valued in practice

- Time allocated to training

- Learning culture

- Evaluation of the impact of training 


\subsubsection{The result criteria}

Figure 2 The result criteria of the e-learning readiness measurement model

\section{Learner characteristics}

- $\quad$ ICT skills of the learners

- Internet experience of the learners

- Motivation for use of e-learning of the trainees

- Do they have a preferred learning style? (prefer presentations including audio, video, ....)

2. Availability of qualitative technological facilities for e-learning

- User ICT infrastructure

- The internet connectivity

- $\quad$ Flexible Learning management system to handle web-based materials

- System to connect learners together

- $\quad$ Tracking the learning activity
3. Organisation and management of e-learning

- Investments in physical environment, good user systems and in e-learning infrastructure

- $\quad$ Learning time during working hours?

- Preparatory training in usage computers and internet

4. E-learning process and solutions/courses

- Organisation of the e-learning activity

- Training in using e-learning system

- Support of the e-learning activity

- Information about available e-learning courses

- User friendly system functions facilitating learning activities

- E-learning course content and presentation

- Level of personalisation of learning

- Matching of course with learning style

- Matching of course with job requirements

\section{Applying ERA to hospitals: the Agfa case}

A study on the adoption of e-learning for public health nurses' continuous education showed an affirmative intention towards adopting e-learning as their way of continuing education ( $\mathrm{Yu}$ et al., 2006). The reasons for adopting e-learning include achieving lifelong learning, fulfilling personal interests, orientation on concrete job needs, demands for information diversity, flexibility in time and space, the possibility of self-regulatory learning, cost-effectiveness and lessening the impact on family duties. The reasons to reject e-learning include poor computer literacy, the lack of personal access to computers with and without internet access, a heavy workload, the lack of motivation and low self-control. On the whole, employees are keen to see e-enabled training and the staff is interested in e-learning. Three in five employees think that e-learning is a practical option in their own organisation (Yu et al., 2006). The healthcare workforce is e-ready. 


\subsection{The case: the e-health services of Agfa}

In collaboration with the company Agfa healthcare, we investigated the e-learning readiness of ten Flemish hospitals that are customers of Agfa healthcare. Agfa healthcare is a leading provider of integrated IT solutions and state-of-the-art diagnostic imaging for hospitals and other healthcare centres. The mission of Agfa healthcare is to support the transformation process of Information and Communication Technology (ICT) solutions that improve the medical care services of hospitals. Recently, Agfa healthcare provides e-learning services to its customers, the hospitals. All ICT solutions will be complemented with an optional e-learning component. The e-learning component can be accessed via an e-learning portal of Agfa healthcare. The hospital can also change from traditional classroom learning to e-learning. The e-learning course also functions as a help tool afterwards.

\subsection{Applying ERA: an e-health case}

Agfa healthcare is convinced of the advantages of using their e-learning solution for hospitals, replacing traditional classroom learning. But are hospitals ready to change? For the analysis, we first selected the relevant criteria from our e-learning readiness measurement instrument. We developed a questionnaire of 80 questions that should assess the e-readiness of the hospitals in several areas. The development of the questionnaire has been based on the criteria that were mentioned earlier in combination with the quality questionnaires of e-learning, which we developed earlier (Schreurs et al., 2008). We checked first for the preferred situation by the radiologist, the head of nursery of the department and the ICT director. Secondly, we asked to do a self-assessment of their skills, motivation, experiences and the like. Thirdly, we asked for the evaluation of the hospital ICT infrastructure to be used for e-learning. Furthermore, we also asked for a judgement from Agfa healthcare regarding the way they are facilitating the e-learning application for the hospital.

\subsection{Results: e-learning readiness in hospitals}

The results of the questionnaire, which was surveyed in ten hospitals, were quite homogeneous. The following sections will discuss the most valid results findings.

\subsubsection{Learner characteristics}

Most employees do not have experience using an e-learning course, although most of them work regularly with personal computers and have knowledge of the standard MS Office software packages.

The learners are not more motivated for e-learning than for a traditional course. It can be explained by the fact that most of them still have no experience with e-learning. It is an opportunity for the hospital management and Agfa healthcare to clarify the advantages of an e-learning solution.

On the point of the preferred learning styles, we see that video fragments are regarded as necessary in an e-learning course and the insertion of simulation modules in the e-learning system creates a large surplus value. However, the results also show that they do not prefer audio above written documents. 
Figure 3 The e-learning readiness measurement instrument measuring the e-readiness in a hospital

\begin{tabular}{|c|c|c|c|c|c|c|c|c|}
\hline \multirow[t]{2}{*}{ Criteria/Subcriteria } & \multicolumn{3}{|c|}{$\begin{array}{c}\text { Professional importance } \\
\text { (scale: } 1 \text { to 4) }\end{array}$} & \multicolumn{2}{|c|}{$\begin{array}{l}\text { Evaluation of } \\
\text { skills level of } \\
\text { learner } \\
\text { (scale: } 1 \text { to 4) }\end{array}$} & \multicolumn{2}{|c|}{$\begin{array}{l}\text { Quality of } \\
\text { e-learning } \\
\text { facilities } \\
\text { (scale: } 1 \text { to 4) }\end{array}$} & \multirow{2}{*}{$\begin{array}{c}\begin{array}{c}\text { Evaluation } \\
\text { facilities by } \\
\text { AGFA }\end{array} \\
\text { AGFA }\end{array}$} \\
\hline & Doctor & Nurse & ICT & Doctor & Nurse & ICT & $\begin{array}{l}\text { Mgmt. } \\
\text { Doctor }\end{array}$ & \\
\hline \multicolumn{9}{|l|}{ Enabling learning resources } \\
\hline $\begin{array}{l}\text { Information on available } \\
\text { learning opportunities }\end{array}$ & $\mathrm{x}$ & $\mathrm{x}$ & & & & & & $\mathrm{x}$ \\
\hline $\begin{array}{l}\text { The electronic online } \\
\text { learning environment }\end{array}$ & & & & & & & & \\
\hline ICT and the learning system & & & $\mathrm{x}$ & & & $\mathrm{x}$ & & $\mathrm{x}$ \\
\hline $\begin{array}{l}\text { System functions facilitate } \\
\text { learning activities }\end{array}$ & & & $\mathrm{x}$ & & & & & $\mathrm{x}$ \\
\hline Maintenance of facilities & & & $\mathrm{x}$ & & & & & $\mathrm{x}$ \\
\hline $\begin{array}{l}\text { The physical learning environment } \\
\text { provided for online session }\end{array}$ & $\mathrm{x}$ & $\mathrm{x}$ & & & & & $\mathrm{X}$ & \\
\hline \multicolumn{9}{|l|}{ Investment in e-learning solutions } \\
\hline $\begin{array}{l}\text { Investments in local central ICT } \\
\text { learning infrastructure for } \\
\text { implementation of e-learning }\end{array}$ & & & $\mathrm{x}$ & & & & $\mathrm{X}$ & \\
\hline $\begin{array}{l}\text { Learners in this new } \\
\text { learning environment }\end{array}$ & & & & & & & & \\
\hline ICT skills of learners & & & & $\mathrm{x}$ & $\mathrm{x}$ & & & \\
\hline Motivation of learners & & & & $\mathrm{x}$ & $\mathrm{x}$ & & & \\
\hline Learning styles of learners & & & & $\mathrm{x}$ & $\mathrm{x}$ & & & \\
\hline \multicolumn{9}{|l|}{ Enabling learning processes } \\
\hline E-learning activities & $\mathrm{x}$ & $\mathrm{x}$ & $\mathrm{x}$ & & & & & $\mathrm{x}$ \\
\hline \multicolumn{9}{|l|}{ Course progression } \\
\hline \multicolumn{9}{|l|}{$\begin{array}{l}\text { Teaching approach/ } \\
\text { course design }\end{array}$} \\
\hline \multicolumn{9}{|l|}{$\begin{array}{l}\text { Personalising the learner's } \\
\text { e-learning course }\end{array}$} \\
\hline $\begin{array}{l}\text { Personalising your } \\
\text { own learning }\end{array}$ & & & & & & & & \\
\hline Learner support & $\mathrm{x}$ & $\mathrm{x}$ & $\mathrm{x}$ & & & & & $\mathrm{x}$ \\
\hline ICT support & & & & & & & & \\
\hline Online support & & & & & & & & \\
\hline \multicolumn{9}{|l|}{ The learning results } \\
\hline Knowledge increase & $\mathrm{x}$ & $\mathrm{x}$ & & & & & & \\
\hline Use of skills learned & $\mathrm{x}$ & $\mathrm{x}$ & & & & & & \\
\hline
\end{tabular}




\subsubsection{Availability of qualitative technological facilities for e-learning}

There are three distinct technological elements which organisations need to address if they are to be ready to deliver e-learning. These include the hardware available to staff, internet connectivity and how flexible the system is to engage with all the web-based material. In the reported case, the physical conditions seem to be evaluated with great importance to the employees and the scores were generally well in Flemish hospitals.

We checked the expected ICT situation, the current situation and the implementation of the Agfa healthcare approach. A first remarkable result is the similarity between the expected situation of the hospitals and the solution for facilitating e-learning as delivered by Agfa healthcare. The results from Agfa healthcare match very well the requirements on the point of ICT infrastructure as formulated by the hospitals. We see a good match between the expected situation and the prospective situation by Agfa healthcare. Although there seems to be a discrepancy between the expected situation and the actual situation, the hospitals are aware that the current situation of the ICT infrastructure is often not sufficient to meet the requirements and that additional investments are required.

We find another remarkable result with the underlying system functions to facilitate e-learning. There is a great discrepancy between the required underlying system functions (average score of 3.2) and the way that Agfa healthcare wishes to facilitate them (average score of 1.0).

On the point of the required elements for a collaborative e-learning approach, we see that in the reported case, those supporting system facilities are wanted by the hospitals but are not facilitated by the supplier. Here, an opportunity can be taken by the supplier to increase the readiness.

On the point of the maintenance of ICT facilities, an average score of the expected situation resulted in 4.0, which is remarkably higher than the average score of 2.5 of Agfa healthcare. This difference can be explained by the scores of the indicator on the 'adjustment of the learning system to new versions of system software'. Also, Agfa healthcare should consider the incorporation of this facility in the package.

\subsubsection{Organisation and management of e-learning}

The wishes of all the staff are quite similar for the physical aspects. The expectations are rather high, which is good in the case of Agfa healthcare because their physical learning environment is already at a high level. The duration of the learning within working hours is preferable and that employees spend more time learning from their offices rather than from their homes. The current ICT infrastructure is not good enough in most cases. ICT is fairly prepared to make investments to upgrade to the necessary level to make e-learning possible and successful.

Because most employees do not have experience using an e-learning course, although most of them work regularly with personal computers and have knowledge of the standard packages, guidance is required. It is very important that the first time they use e-learning, they be guided and they prefer a classroom session organised in advance for them to be coached and for the use of the system to be enhanced. It is recommendable that the key users will be thoroughly coached when they have no experience with e-learning. 


\subsubsection{Learning during office time}

\section{E-learning process and solutions/courses}

On the point of the availability of information on the training supply, they all agreed that the composition of the e-learning package must be made clear. Accordingly, Agfa healthcare can satisfy its customers by composing a clear overview of the available e-learning solutions. We see a remarkable difference in the results between the demand by the hospital and the supply by Agfa healthcare on the point of the personalisation of the e-learning courses. The hospitals want a reasonable personalisation of the course, in contrast with Agfa healthcare, who does not wish to incorporate personalisation. By including the facility of personalisation in their e-learning solution, Agfa healthcare should contribute to the e-learning readiness of the hospitals.

We see the same gap on the point of 'self-management of the learning process', but the hospital is not convinced about the value of it. On this matter, Agfa healthcare thinks that it is very important, in contrast with the hospitals, who rate it low. The aspect of supporting the learner in using the ICT infrastructure as well as in using the e-learning system functions is considered important for all users in the hospital. Also, Agfa healthcare considers this as less important.

On the point of matching the learning styles of the learners, we identified that video fragments were regarded necessary in an e-learning course and the insertion of simulation modules in the e-learning system should create a large surplus value. We can say that if those two items are integrated in the e-learning course, the readiness of the users will increase.

\section{Enabling the employees/learners to participate in an e-learning course}

In the reported case, e-learning is not yet seen as being more motivational than traditional learning. The advantages of e-learning have to be well pointed out. A challenge for the Flemish hospitals is to convince their employees to participate in e-learning courses. We saw that the management of the hospitals believe in the added value of the implementation of e-learning courses. The management is prepared to facilitate e-learning by the organisation of courses in ICT and internet usage for the employees/learners. The management is prepared to invest in a new ICT infrastructure.

Training activity in the organisation is a management issue

We focused our research on the radiology department of the hospitals. The enlargement of knowledge of the used systems and the possibility of its application in the department is straightforward. A resulting deep knowledge is set forward by the head of the department.

The organisational learning culture or attitude to e-learning in the hospitals is about the learning environment it fosters, the applicability of on-the-job training in the organisation and the way the organisation evaluates the impact of training. In the reported case, we have not focused on this aspect because we have only included one department in this research that was relevant for this e-learning application. 


\section{Conclusions}

The hospitals are aware that the implementation of relevant e-learning courses will add value to the organisation, although e-learning is not yet implemented in most hospitals.

Agfa healthcare is a leading provider of integrated IT solutions and state-of-the-art diagnostic imaging for hospitals and other healthcare centres. The mission of Agfa healthcare is to support the transformation process of the adoption of ICT solutions that improve the medical care services of hospitals. Recently, Agfa healthcare provides e-learning services to its customers, the hospitals.

Before implementing the e-learning course, it must be known if the hospital is ready for its implementation or if the hospital has a good e-learning readiness level.

We developed an e-learning readiness measurement model and a readiness measurement instrument especially for hospitals.

We do not have a complete view of the enabling site from the point of view of the learning culture of the hospital, though we see a great potential and need for e-learning in the department of radiology and that the management is prepared to invest in the needed infrastructure.

To reach a high level of readiness, work has to be done on the point of preparatory training of the users in using e-learning systems. Also, a clear policy on the spending of time on e-learning during office hours is needed. An important aspect is the e-learning solution itself. It seems that there is still a gap between the delivered solutions and the required ones. A discussion with the supplier is crucial to develop an e-learning solution that can be adapted to the healthcare sector.

\section{References}

Aydin, C.H. and Tasci, D. (2005) 'Measuring readiness for e-learning: reflections from an emerging country', Educational Technology \& Society, Vol. 8, No. 4, pp.244-257.

Bernhardt, J.M., Runyan, C.W., Bou-Saada, I. and Felter, E.M. (2003) 'Implementation and evaluation of a web-based continuing course in injury prevention and control', Health Promotion Practice, Vol. 4, No. 2, pp.120-128.

Bowles, M. (2004) Relearning to E-learn: Strategies for Electronic Learning and Knowledge, Melbourne University Press.

Ipsos MORI (2006) 'E-readiness in the social sector', Social Care Institute for Excellence (SCIE), December, http://www.scie.org.uk/publications/consultation/readiness.pdf.

Powell, G.C. (2000) 'Are you ready for web-based training?', Educational Technology \& Society, Vol. 3, No. 1, pp.52-55.

Psycharis, S. (2005) 'Presumptions and actions affecting an e-learning adoption by the educational system. Implementation using virtual private networks', Eurodl, http://www.eurodl.org/materials/contrib/2005/Sarantos_Psycharis.htm.

Schreurs, J., Husson, A.M., Merison, B., Morin, E. and Van Heysbroeck, H. (2008) 'SEVAQ: a unique multi-functional tool for assessing and improving the quality of e-courses', Int. J. Emerging Technologies in Learning, Vol. 3, No. 1.

Yu, S., Chen, I-J., Yang, K-F., Wang, T-F. and Yen, L-L. (2007) 'A feasibility study on the adoption of e-learning for public health nurse continuing education in Taiwan', Nurse Education Today, Vol. 27, No. 7, pp.755-761. 


\section{Bibliography}

Ong, C-S., Lai, J-Y. and Wang, Y-S. (2004) 'Factors affecting engineers' acceptance of asynchronous e-learning systems in high-tech companies', Information \& Management, Vol. 41, No. 6, pp.795-804.

Ellis, M. (2007) 'Changing the face of traditional education: a framework for adapting a large, residential course to the web', Eleed Journal, http://eleed.campussource.de/archive/3/1081/.

Ghanam, D. and Cox, P. (2007) 'Dynamic capabilities: the strategy-HRM intersect?', Int. J. Learning and Intellectual Capital, Vol. 4, Nos. 1-2, pp.57-74.

Kenny, C. and Pahl, C. (2008) 'Personalised correction, feedback and guidance in an automated tutoring system for skills training', Int. J. Knowledge and Learning, Vol. 4, No. 1, pp.75-92.

Koo, A-C. (2008) 'Factors affecting teachers' perceived readiness for online collaborative learning: a case study in Malaysia', Educational Technology \& Society, Vol. 11, No. 1, pp.266-278.

Lytras, M. and Sicilia, M. (2005) 'Knowledge society a manifesto for knowledge and learning', Int. J. Knowledge and Learning, Vol. 1, No. 1, pp.1-11.

Lytras, M.D. (2007) 'Teaching in the knowledge society: an art of passion', Int. J. Teaching and Case Studies, Vol. 1, Nos. 1-2, pp.1-9.

Moolman, H.B. and Blignaut, S. (2008) 'Get set! E-ready, ...e-learn! The e-readiness of warehouse workers', Technology \& Society, Vol. 11, No. 1, pp.168-182.

Mungania, P. (2003) The Seven E-Learning Barriers Facing Employees, The Masie Centre, E-Readiness in the Social Care Sector.

Ozdemir, Z. and Abrevaya, J. (2007) 'Adoption of technology-mediated distance education: a longitudinal analysis', Information \& Management, July, Vol. 44, No. 5, pp.467-479.

Ozdemir, Z., Altynkemer, K. and Barron, J. (2008) 'Adoption of technology-mediated learning in the USA', Decision Support Systems Journal, May, Vol. 45, No. 2, pp.324-337.

Snae, C. and Brueckner, M. (2007) 'Ontology-driven e-learning system based on roles and activities for Thai learning environment', Interdisciplinary Journal of Knowledge and Learning Objects, Vol. 3.

Sun, P.Y.T. and Scott, J.L. (2006) 'Process level integration of organisational learning, learning organisation and knowledge management', Int. J. Knowledge and Learning, Vol. 2, Nos. 3-4, pp.308-319.

\section{Note}

1 www.scie.org.uk/publications/consultation/readiness.pdf 